\title{
Comparative analysis of Duroc and Pietrain boar sperm morphology
}

\author{
Stanisław Kondracki, Maria Iwanina, Anna Wysokińska, Małgorzata Huszno \\ Department of Animal Reproduction and Hygiene, Faculty of Life Sciences, Siedlce University of Natural Sciences \\ and Humanities, Poland
}

Received July 1, 2010

Accepted April 11, 2012

\begin{abstract}
The aim of this study was to compare ejaculates of Duroc and Pietrain boars in terms of sperm morphology characteristics. Analysis was performed on 116 ejaculates collected from 6 Duroc boars and 9 Pietrain boars. The boars selected for examination were young and the beginning of their reproductive utilization. Ejaculates were collected at monthly intervals over the period of 10 months. Microscopic slides were prepared immediately after collection of ejaculates. The slides were examined to assess the frequency of morphological abnormalities. Moreover, morphometric measurements were taken from 15 randomly selected morphologically normal spermatozoa. Also, conventional evaluation of ejaculates was made following methods used at Polish sow insemination centres. Differences were found in the dimensions and shape between Duroc and Pietrain spermatozoa. Pietrain spermatozoa were characterised by significantly smaller head perimeter compared with Duroc $(P \leq 0.01)$. Moreover, Pietrain spermatozoa tails were by 0.8 $\mu \mathrm{m}$ longer $(P \leq 0.01)$, and their total sperm length was greater by $0.5 \mu \mathrm{m}$ compared to Duroc $(P \leq 0.05)$ sperm. The volume of Duroc ejaculates was lower but their sperm concentration was greater. The results of the present study contribute to scientific progress as they demonstrate differences in sperm size between boars of different breeds, which may be reflected in different reproductive performances of the boars.
\end{abstract}

Pigs, purebreed, ejaculate, morphometry

The breeding value of boar depends on the quantity and quality of semen produced. Ejaculate variation is the product of an influence of many factors including race (Smital et al. 2004), season of the year (Wysokińska et al. 2009b), boar age (Deka et al. 2002) as well as utilization intensity (Frangez et al. 2005). Depending on the breed, ejaculates have different volumes, semen concentrations and percentages of progressively motile spermatozoa. There are also differences in fertilization efficiency, fertility and overall semen evaluation.

The aim of this study was to comparatively analyse Duroc and Pietrain boars used for artificial insemination in terms of sperm morphology.

\section{Materials and Methods}

The study was conducted on 8-9-month-old boars at the initial stage of their reproductive utilization. A total of 116 ejaculates were examined. They were collected from 6 Duroc and 9 Pietrain boars utilized at two sow artificial insemination stations owned by the Mazovian Centre of Animal Breeding and Reproduction in Lowicz, Poland. Ejaculates were collected at monthly intervals with the "gloved-hand" method during the period of 10 months. Immediately after collection one microscopic slide for examinations was prepared from each ejaculate. A thin sperm smear was applied to a degreased microscope slide and fixed in a $96 \%$ ethanol solution for $5 \mathrm{~min}$. Then, the preparation was rinsed in distilled water and stained with a $10 \%$ eosin aqueous solution for 20-60 s. The stained preparations were rinsed in distilled water and stained with gentian-violet dye for 3-5 min. After staining the preparations were rinsed, dried and examined under the microscope. All the samples were microscopically analysed using $\times 100$ immersion lens and a microscope Nikon E-400. Morphology of 500 spermatozoa was evaluated in each sample and spermatozoa with normal morphology and with primary and secondary changes were determined following the Blom classification system (Blom 1981). Moreover, in each preparation morphometric measurements were taken from 15 randomly selected spermatozoa with normal morphology by means of software for computer image

Address for correspondence:

Stanisław Kondracki

Department of Animal Reproduction and Hygiene, Faculty of Life Sciences

Siedlce University of Natural Sciences and Humanities

Prusa 14 Street, 08-110 Siedlce, Poland

Phone/fax: +48256431272

E-mail: sk@ap.siedlce.pl

http://actavet.vfu.cz/ 
analysis (Screen Measurement v. 4. 1). Following the method of Kondracki et al. (2005), the following spermatozoa measurements were taken: sperm head length, sperm head width, head area, tail length, sperm head perimeter, and total sperm length.

Immediately after collection, the ejaculates were also used to determine the following physical characteristics: ejaculate volume (in $\mathrm{ml}$ ), sperm concentration (in th/ $\mathrm{mm}^{3}$ ), percentage of spermatozoa with normal motility, total number of spermatozoa in ejaculate and number of insemination doses obtained from one ejaculate.

The results were statistically analysed according to the following model: $Y_{i j}=\mu+a_{i}+e_{i}$

where, $\mathrm{Y}_{\mathrm{ij}}$ - value of the characteristic examined, $\mu$ - population mean, $\mathrm{a}_{\mathrm{i}}-$ boar breed effect, $\mathrm{e}_{\mathrm{ij}}-$ error. Significance of between-group differences was verified by means of Tukey's test at $P \leq 0.05$ and $P \leq 0.01$.

\section{Results}

Table 1 presents data on the frequency of sperm morphological abnormalities in ejaculates of Duroc and Pietrain boars. The data indicate that both breeds produced ejaculates of good quality. The percentage of spermatozoa with normal morphology in Duroc and Pietrain semen was as high as $94.02 \%$. Pietrain boars' ejaculates had slightly more spermatozoa with primary abnormalities but less spermatozoa with secondary abnormalities compared to Duroc boars. However, the differences were small and were non-significant $(P>0.05)$. Of the spermatozoa with primary abnormalities, the largest was the percentage of spermatozoa with a closer proximal protoplasmic droplet on the mid-piece and the spermatozoa with strongly coiled tails. In Pietrain boar ejaculates more spermatozoa were found with strongly coiled tail $(0.15 \%)$ compared to Duroc ejaculates $(P \leq 0.05)$. However, the percentage of spermatozoa with this defect was low and in neither breed was it larger than $0.5 \%$ of the spermatozoa examined. Pietrain ejaculates contained by $0.75 \%$ more spermatozoa with lose normal heads than Duroc ejaculates $(P \leq 0.05)$. Of the spermatozoa with secondary abnormalities, the largest was the percentage of spermatozoa with further

Table 1. Frequency of occurrence (means \pm SD) of normal and abnormal spermatozoa in ejaculate of Pietrain and Duroc boars

\begin{tabular}{lcc}
\hline Variable & & Breed \\
\cline { 2 - 3 } & Pietrain & Duroc \\
\hline Number of ejaculates & 63 & 53 \\
\hline Percentage of normal spermatozoa & $94.02 \pm 5.64^{\mathrm{a}} \pm 4.28^{\mathrm{a}}$ \\
Sperm with primary abnormalities (\%) & $1.39 \pm 1.94^{\mathrm{a}}$ & $1.06 \pm 2.02^{\mathrm{a}}$ \\
Retarded sperm & $0.08 \pm 0.29^{\mathrm{a}}$ & $0.03 \pm 0.7^{\mathrm{a}}$ \\
Double forms & $0.06 \pm 0.28^{\mathrm{a}}$ & $0.04 \pm 0.11^{\mathrm{a}}$ \\
Pear shaped head & $0.05 \pm 0.15^{\mathrm{a}}$ & $0.08 \pm 0.28^{\mathrm{a}}$ \\
Spermatozoa with narrow head & $0.07 \pm 0.28^{\mathrm{a}}$ & $0.02 \pm 0.05^{\mathrm{a}}$ \\
Abnormal contour & $0.04 \pm 0.12^{\mathrm{a}}$ & $0.02 \pm 0.05^{\mathrm{b}}$ \\
Small abnormal heads & $0.05 \pm 0.28^{\mathrm{a}}$ & $0.01 \pm 0.06^{\mathrm{a}}$ \\
Spermatozoa with proximal droplet & $0.65 \pm 1.58^{\mathrm{a}}$ & $0.66 \pm 1.91^{\mathrm{a}}$ \\
Spermatozoa with pseudodroplet & $0.06 \pm 0.15^{\mathrm{a}}$ & $0.02 \pm 0.11^{\mathrm{b}}$ \\
Spermatozoa with strongly coiled trail & $0.33 \pm 0.61^{\mathrm{a}}$ & $0.18 \pm 0.30^{\mathrm{b}}$ \\
Sperm with secondary abnormalities $(\%)$ & $4.59 \pm 4.59^{\mathrm{a}}$ & $5.41 \pm 4.03^{\mathrm{a}}$ \\
Giant and short, broad head & $0.02 \pm 0.06^{\mathrm{a}}$ & $0.07 \pm 0.12^{\mathrm{b}}$ \\
Spermatozoa with free heads & $0.49 \pm 0.89^{\mathrm{a}}$ & $1.24 \pm 1.93^{\mathrm{b}}$ \\
Spermatozoa with distal droplets & $2.28 \pm 3.58^{\mathrm{a}}$ & $2.45 \pm 2.88^{\mathrm{a}}$ \\
Spermatozoa with simple bent tail & $1.76 \pm 2.01^{\mathrm{a}}$ & $1.61 \pm 2.33^{\mathrm{a}}$ \\
Spermatozoa terminally coiled tail & $0.04 \pm 0.11^{\mathrm{a}}$ & $0.04 \pm 0.17^{\mathrm{a}}$ \\
\hline
\end{tabular}

Different superscripts mean significant differences among means within particular rows, a,b - significant difference $P \leq 0.05$ 
Table 2. Morphometric characteristics (means \pm SD) of spermatozoa in ejaculate of Pietrain and Duroc boars

\begin{tabular}{lcc}
\hline Variable & \multicolumn{2}{c}{ Breed } \\
\cline { 2 - 3 } & \multicolumn{1}{c}{ Pietrain } & Duroc \\
\hline Number of ejaculates & 63 & 53 \\
\hline Head length $(\mu \mathrm{m})$ & $9.20 \pm 0.39^{\mathrm{A}}$ & $9.41 \pm 0.31^{\mathrm{B}}$ \\
Flagellum length $(\mu \mathrm{m})$ & $44.52 \pm 1.72^{\mathrm{A}}$ & $43.72 \pm 1.09^{\mathrm{B}}$ \\
Head width $(\mu \mathrm{m})$ & $4.65 \pm 0.25^{\mathrm{A}}$ & $4.80 \pm 0.18^{\mathrm{B}}$ \\
Head perimeter $(\mu \mathrm{m})$ & $23.82 \pm 1.02^{\mathrm{A}}$ & $24.17 \pm 0.88^{\mathrm{B}}$ \\
Head area $\left(\mu \mathrm{m}^{2}\right)$ & $40.47 \pm 2.72^{\mathrm{a}}$ & $40.73 \pm 1.18^{\mathrm{a}}$ \\
Total length $(\mu \mathrm{m})$ & $53.72 \pm 1.79^{\mathrm{a}}$ & $53.20 \pm 1.35^{\mathrm{b}}$
\end{tabular}

Different superscripts mean significant differences among means within particular rows, $\mathrm{a}, \mathrm{b}-P \leq 0.05$;

A, B $-P \leq 0.01$

distal protoplasmic droplet on the mid-piece as well as spermatozoa with single-coiled tails.

Table 2 demonstrates data on spermatozoa morphometric characteristics of Duroc and Pietrain boars. The spermatozoa of both breeds were of different sizes. Pietrain spermatozoa had shorter and narrower heads compared to Duroc $(P \leq 0.01)$. As a result, Pietrain spermatozoa were characterised by significantly smaller head perimeter compared to Duroc $(P \leq 0.01)$. Moreover, Pietrain spermatozoa tails were by $0.8 \mu \mathrm{m}$ longer $(P \leq 0.01)$, and had by $0.5 \mu \mathrm{m}$ greater total sperm length compared to Duroc $(P \leq 0.05)$ sperm.

Table 3 presents data on physical characteristics of ejaculates collected from Duroc and Pietrain boars. The data indicate that the ejaculates of the boars examined in the study differed in physical properties. Compared to Pietrain, the volume of ejaculates of Duroc boars was lower by more than $90 \mathrm{ml}$ but the spermatozoa concentration was higher by more than $100 \mathrm{th} / \mathrm{mm}^{3}(P \leq 0.01)$. Pietrain boar ejaculates had by approximately $10 \mathrm{mld}$ more spermatozoa than Duroc ejaculates $(P \leq 0.01)$. One ejaculate collected from Pietrain males yielded by over 6 insemination doses more compared to Duroc ejaculates $(P \leq 0.01)$.

Table 3. Physical characteristics (means $\pm \mathrm{SD}$ ) of ejaculates of Duroc and Pietrain boars

\begin{tabular}{lcc}
\hline Variable & \multicolumn{2}{c}{ Breed } \\
\cline { 2 - 3 } & Pietrain & Duroc \\
\hline Number of ejaculates & 63 & 53 \\
\hline Ejaculate volume $(\mathrm{ml})$ & $276.03 \pm 103.50^{\mathrm{A}}$ & $185.28 \pm 57.03^{\mathrm{B}}$ \\
Sperm concentration $\left(\times 10^{3} / \mathrm{mm}^{3}\right)$ & $444.29 \pm 101.44^{\mathrm{A}}$ & $548.79 \pm 136.01^{\mathrm{B}}$ \\
Percentage of spermatozoa with normal motility $(\%)$ & $79.21 \pm 2.72^{\mathrm{A}}$ & $80.00 \pm 0.00^{\mathrm{B}}$ \\
Total number of spermatozoa $\left(\times 10^{9}\right)$ & $90.81 \pm 28.92^{\mathrm{A}}$ & $80.45 \pm 26.68^{\mathrm{B}}$ \\
Number of insemination doses per ejaculate & $29.92 \pm 8.99^{\mathrm{A}}$ & $23.66 \pm 7.57^{\mathrm{B}}$ \\
\hline
\end{tabular}

Different superscripts mean significant differences among means within particular rows, A,B - $P \leq 0.01$

\section{Discussion}

We observed slight relation between the frequency of spermatozoa morphological abnormalities and boar breed. Spermatozoa defects, classified as primary abnormalities, are particularly important because most frequently they take place during spermatogenesis. The number of these abnormalities influences the fertilizing ability of sperm, which is synonymous with boar prolificacy (Colenbrander and Kemp 1990). The data presented 
in this paper showed that the proportion of spermatozoa with primary abnormalities was low and did not exceed $1.4 \%$ in either breed. Results of our study demonstrated differences in spermatozoa dimensions and shape between Duroc and Pietrain breeds. Spermatozoa dimensions may be associated with sperm numbers (Wysokińska et al. 2009a). The dimensions, in addition to spermatozoa liveability and motility, are important factors of post-copulation semen selection (Snook 2005). Pietrain spermatozoa had longer tails than Duroc, which may indicate that they were more motile. According to Gomendio and Roldan (1991), spermatozoon velocity depends on the length. Research by Bierła and Giżejewski (2007) has revealed that tail length is associated with a different amount of energy produced in mitochondria, which results in different motility of spermatozoa. Spermatozoa dimensions can depend on spermatozoa concentration in ejaculate (Rijsselaere et al. 2004). The data presented in this work demonstrated that Pietrain spermatozoa had a smaller head perimeter compared to Duroc spermatozoa. The sperm head is the genetic information carrier during the fertilization process so its size and shape may play an important role in this process. Some authors believe that head shape is associated with chromatin structure and integrity and, as a result, male prolificacy (Ostermeier et al. 2001). Spermatozoa of highly fertile boars have got smaller and shorter heads compared to spermatozoa of boars that are less effective in terms of fertilizing performance (Hirai et al. 2001). Saravia et al. (2007) have reported that dimensions of a spermatozoa head, i.e. its length, width, area and perimeter, are larger for Duroc boars compared to other breeds (Risco-hybrid, Large White, Landrace and Yorker-hybrid) examined in their study. The finding is in line with the results of our study and might indicate that Duroc boars are characterised by poorer fertility.

Data from our study indicate that there are distinct differences in the ejaculate volume between Duroc and Pietrain boars. Pietrain ejaculates were characterised by more favourable quantitative characteristics. The volume of ejaculates produced by Duroc boars was lower but the sperm concentration was higher compared to Pietrain. Similar findings have been reported by Smital (2009) and Leidinger et al. (1998) who have demonstrated that high sperm concentration in volume was a significant characteristic of Duroc sperm. Ejaculates characterized by high sperm concentration and low volume yield less insemination doses. Ejaculates of Pietrain boars contained more spermatozoa than Duroc ejaculates. One ejaculate collected from Pietrain boars yielded by over 6 insemination doses more compared to Duroc boars. It is a distinctive characteristic of the Pietrain breed (Smital 2009) which is of economic importance due to the number of insemination doses. This property is therefore crucial for the profitability of boar utilization.

There are significant differences in spermatozoa morphometry and physical characteristics of ejaculate between Duroc and Pietrain boars. Duroc spermatozoa have slightly larger heads that are significantly longer, have a larger perimeter and shorter tails, compared to Pietrain spermatozoa. By contrast, no differences were found between the breeds as to the frequency of spermatozoa morphological abnormalities. Low volume of Duroc ejaculates was accompanied by high spermatozoa concentration. Ejaculates of Pietrain boars contained more spermatozoa compared to Duroc males.

\section{References}

Bierła JB, Giżejewski Z 2007: Plemnik plemnikowi nierówny - fizjologia czy patologia? [Differences in spermatozoon: physiology or pathology?] Med Wet 63: 1408-1411

Blom E 1981: Ocena morfologiczna wad plemników buhaja II. Propozycja nowej klasyfikacji wad plemników [The morphological estimation of the spermatozoa defects of bull II]. Med Wet 37: 239-242

Colenbrander B, Kemp B 1990: Factors influencing semen quality in pigs. J Reprod Fertil Suppl 40: 105-115

Deka D, Goswami RN, Mili DC, Nath DR 2002: Effect of age of the sow and boar on reproduction performance. Indian Vet J 79: 615-616 
Frangez R, Gider T, Kosec M 2005: Frequency of boar ejaculate collection and its influence on semen quality, pregnancy rate and litter size. Acta Vet Brno 74: 265-273

Gomendio M, Roldan ERS 1991: Sperm competition influences sperm size in mammals. Proc R, Soc Lond B Biol Sci 243: 181-185

Hirai M, Boersma A, Hoeflich A, Wolf E, Föll J, Aumüller TR, Braun AJ 2001: Objectively measured sperm motility and sperm head morphometry in boars (Sus scrofa): Relation to fertility and seminal plasma growth factors. J Androl 22: 104-110

Kondracki S, Banaszewska D, Mielnicka C 2005: The effect of age on the morphometric sperm traits of domestic pigs. Cell Mol Biol Lett 1: 3-13

Leidinger H, Reiner G, Krapoth I, Dzapo V 1998: Beziehungen zwischen Spermatozoenvolumen und Eberfruchtbarkeit. [Relations between spermatozoa volume and fertility in boars]. Arch Tierz 41: 65-73

Ostermeier GC, Sargeant GA, Yandell BS, Evenson DP, Parrish JJ 2001: Relationship of bull fertility to sperm nuclear shape. J Androl 22: 595-603

Rijsselaere T, Van Soom A, Hoflack G, Maes D, Kruif A 2004: Automated sperm morphometry and morphology analysis of canine semen by the Hamilton-Thorne analyser. Theriogenology 62: 1292-1306

Saravia F, Nứñez-Martínez I, Moran JM, Soler C, Muriel A, Rodríguez-Martínez H, Peña FJ 2007: Differences in boar sperm head shape and dimensions recorded by computer-assisted sperm morphometry are not related to chromatin integrity. Theriogenology 68: 196-203

Smital J, De Sousa LL, Mohnsen A 2004: Differences among breeds and manifestation of heterosis in AI boar sperm output. Anim Reprod Sci 80: 121-130

Smital J 2009: Effects influencing boar semen. Anim Reprod Sci 110: 335-346

Snook RR 2005: Sperm competition: not playing by the numbers. Trends Ecol Evol 20: 46-53

Wysokińska A, Kondracki S, Banaszewska D 2009a: Morphometrical characteristics of spermatozoa in Polish Landrace boars with regard to the number of spermatozoa in an ejaculate. Rep Biol 9: 271-282

Wysokińska A, Kondracki S, Kowalewski D, Adamiak A, and Muczyńska E 2009b: Effect of seasonal factors on the ejaculate properties of crossbred Duroc x Pietrain and Pietrain x Duroc boars as well as purebred Duroc and Pietrain boars. Bull Vet Inst Pulawy 53: 677-685 